\title{
New protective antigen of group A streptococci
}

\author{
James B. Dale, ${ }^{1,2}$ Edna Y. Chiang, ${ }^{1}$ Shaoyou Liu, ${ }^{1}$ Harry S. Courtney, ${ }^{1,2}$ \\ and David L. Hasty ${ }^{2,3}$
}

${ }^{1}$ Veterans Affairs Medical Center, Memphis, Tennessee 38104, USA

${ }^{2}$ Department of Medicine, and

${ }^{3}$ Department of Anatomy and Neurobiology, University of Tennessee, Memphis, Tennessee 38104, USA

Address correspondence to: James B. Dale, Veterans Affairs Medical Center (11A), 1030 Jefferson Avenue, Memphis, Tennessee 38104, USA. Phone: (901) 577-7207; Fax: (901) 448-8231; E-mail: james.dale@med.va.gov

Received for publication September 3, 1998, and accepted in revised form March 23, 1999.

\begin{abstract}
It is widely believed that the surface $M$ protein of group A streptococci is the predominant surface protein of these organisms containing opsonic epitopes. In the present study, we identified a new surface protein, distinct from $\mathrm{M}$ protein, that evokes protective antibodies. A type $18 \mathrm{M}$-negative mutant was found to be both resistant to phagocytosis in human blood and virulent in mice. The wild-type strain, but not the M-negative mutant, was opsonized by antisera against purified recombinant M18 protein or a synthetic peptide copying the $\mathrm{NH}_{2}$-terminus of M18. However, antisera raised against a crude pepsin extract of the M-negative mutant opsonized both strains, indicating the presence of a protective antigen in addition to type $18 \mathrm{M}$ protein. This antiserum was used to identify and purify a $24-\mathrm{kDa}$ protein fragment (Spa, streptococcal protective antigen) that evoked antibodies that opsonized the M18 parent and the M-negative mutant. The results of passive mouse protection tests confirmed the presence of protective epitopes within Spa. The deduced amino acid sequence of a 636-bp 5' fragment of the spa18 gene showed no homology with sequences in GenBank. These studies reveal the presence of a new protective antigen of certain strains of group A streptococci that may prove to be an important component of vaccines to prevent streptococcal infections.
\end{abstract}

J. Clin. Invest. 103:1261-1268 (1999).

\section{Introduction}

Group A streptococcal infections cause a wide array of clinical syndromes; these range from uncomplicated pharyngitis and pyoderma to serious, invasive infections and toxic shock syndrome. Protection against infection is largely mediated by antibodies against the surface $\mathrm{M}$ protein of the organisms. The M protein is an $\alpha$-helical, coiled-coil molecule that extends from the surface with its hypervariable $\mathrm{NH}_{2}$-terminus exposed to the outside and its conserved $\mathrm{COOH}$-terminus buried in the cytoplasm (1). The $\mathrm{NH}_{2}$-terminus contains type-specific epitopes evoking bactericidal antibodies that correlate with protection against the homologous serotype (2). The $\mathrm{emm}$ gene is located in a regulon controlled by the upstream positive regulator $m g a$ (3). Depending on the serotype, the regulon may contain 1,2 , or $3 \mathrm{emm}$ and $\mathrm{emm}$-like genes (4). In serotypes containing only $1 \mathrm{emm}$ gene, deletion (5) or interruption (6) of the emm gene results in an avirulent organism that can no longer resist phagocytosis. In serotypes expressing several emm-like genes, each may partially contribute to phagocytosis resistance (7), but among the many defined surface proteins of group A streptococci, only antibodies against the $\mathrm{M}$ protein have been shown to be opsonic.

In this study, we identify a new surface antigen, streptococcal protective antigen (Spa) of group A streptococ$\mathrm{ci}$, that evokes protective antibodies. A fully virulent $\mathrm{M}$ negative mutant of type 18 streptococci was opsonized by rabbit antiserum raised against a crude pepsin extract of the M-negative mutant. This antiserum was used to identify and purify the new protective antigen, Spa. Anti- serum against the purified Spa protein was bactericidal against both the type 18 parent strain and, importantly, the M-negative mutant. Passive mouse protection tests using rabbit antisera raised against purified Spa confirmed that the new surface protein contained protective epitopes. In addition, the anti-Spa antibodies opsonized type 3 and type 28 streptococci, indicating that this new surface protein is a cross-protective antigen for certain strains of group A streptococci.

\section{Methods}

Bacterial strains. The parent type 18 streptococcal strain 87-282, has been the subject of previous studies in this laboratory (8) and others (9) and was obtained from Patrick Cleary (University of Minnesota, Minneapolis, Minnesota, USA). The M3 strain (3375) was provided by James Musser (Baylor College of Medicine, Houston, Texas, USA). The M28 strain (S2356) was from our laboratory collection.

Reagents. The preparation of rabbit antisera against the synthetic peptide SM18(1-30)C has been described previously (8). Antisera were also raised against recombinant M18 that was purified from periplasmic extracts of Escherichia coli, as previously described $(8,10)$. Rabbit antisera were similarly prepared against purified $\mathrm{Spa}(8)$. A peptide copying the $\mathrm{NH}_{2}$-terminal 23 amino acid residues of Spa [S-Spa18(1-23)C] was commercially synthesized (Research Genetics Inc., Huntsville, Alabama, USA) and chemically coupled to KLH by methods described previously (11). Antisera against S-Spa18(1-23)C-KLH were raised in rabbits according to our standard, published protocol (11).

Insertion of the $\Omega$-interposon into emm 18 and transformation of type 18 streptococci. Insertional inactivation of emm 18 was accomplished essentially as described previously for type 24 streptococci (6). Briefly, emm 18 was ligated into pKK223-3 and then 
Table 1

Growth of M18 and M18 $\Omega$ streptococci in human blood

\begin{tabular}{lccc} 
& & \multicolumn{2}{c}{ CFU surviving 3-hour rotation ${ }^{\mathrm{A}}$} \\
Organism & \multicolumn{2}{c}{ (no. of generations) } \\
& Inoculum: & 45 & 15 \\
M18 & $12,550(8.1)$ & $4,800(8.3)$ \\
& & 55 & 20 \\
M18 $\Omega$ & Inoculum: & $9,940(7.3)$ & $4,210(7.6)$ \\
\hline
\end{tabular}

${ }^{A}$ Streptococci were grown to early log-phase in Todd-Hewitt broth, and the inoculum indicated was added to $0.45 \mathrm{~mL}$ normal, heparinized human blood that did not contain $\mathrm{M} 18$ antibodies. The mixture was rotated end-over-end at $37^{\circ} \mathrm{C}$ for 3 hours. Surviving organisms were quantitated on pour plates of sheep blood agar using an aliquot of the mixture. The experiment was performed on 3 separate occasions, and the results shown are from a representative experiment. Although the absolute number of CFU varied somewhat from one experiment to another, growth in blood, as determined by the number of generations, was comparable.

cut with XhoI, which recognizes a single site between bases 136 and 141 of the $e m m 18$ gene. The ends were repaired with a Klenow fragment (12). pBR322- $\Omega \mathrm{Km} 2$ was digested with $S m a \mathrm{I}$, and the $\Omega \mathrm{Km} 2$ fragment was purified from a $0.8 \%$ agarose gel and ligated into the cut emm 18 gene (12). The resulting plasmid, pKKM18 $\Omega$, was electroporated into type 18 streptococci as described (6). One kanamycin-resistant colony, designated $\mathrm{M} 18 \Omega$, was selected for further study.

Southern blots. Streptococcal chromosomal DNA was digested with $\mathrm{Bsa \textrm {HI }}$ and electrophoresed in a $1 \%$ agarose gel. The DNA fragments were transferred to a nylon membrane (Sigma Chemical Co., St. Louis, Missouri, USA) and probed with digoxigenin-labeled $\Omega \mathrm{Km} 2$ fragment or emm 18 according to instructions provided by the manufacturer (Boehringer Mannheim Biochemicals, Indianapolis, Indiana, USA).

Western blots. Western blots were performed using extracts of intact streptococci and purified proteins as described previously (13). In some experiments using purified recombinant Enn18 protein, the nitrocellulose membranes were first incubated in buffer containing $10 \%$ normal human serum to block nonspecific binding of immunoglobulins.

Cloning and sequencing enn18. The type 18 strain (87-282) used for these studies contains an M-like gene, enn18, downstream from the emm 18 gene (4). Although Enn18 has been shown to be expressed only in low levels by this strain of group A streptococci (14), we cloned the enn 18 gene and purified the recombinant protein from extracts of E. coli. The purified Enn18 was used in subsequent experiments to determine whether Spa antibodies cross-reacted with this additional surface protein. The enn 18 gene was initially cloned by PCR using a forward primer that copied the $3^{\prime}$ end of the emm 18 gene and a reverse primer that was specific for the SF3 subfamily of emm-like genes (4). The purified PCR product was ligated into pKK223-3, and the insert was sequenced by standard methods (12). The intact enn 18 gene was later cloned using a reverse primer that copied the $5^{\prime}$ end of the scpA gene (15), and the purified PCR product was ligated into PQE-30 (QIAGEN Inc., Chatsworth, California, USA). The recombinant Enn 18 protein was purified by affinity chromatography over a nickel column according to the instructions provided by QIAGEN Inc.

Opsonization and bactericidal assays. In vitro opsonization assays and bactericidal assays were performed using nonimmune whole human blood as described previously (16). Briefly, rotation mixtures contained $0.1 \mathrm{~mL}$ of test antiserum, a standard inoculum of streptococci, and $0.4 \mathrm{~mL}$ of heparinized $(10 \mathrm{U} / \mathrm{mL})$ human blood. For opsonization assays, the number of streptococcal CFUs per leukocyte in the mixture was approximately 10 . The tubes were rotated end-over-end for 45 minutes at $37^{\circ} \mathrm{C}$; smears were then made on glass slides and stained with
Wright's stain. Opsonization was quantitated by counting 50 neutrophils per slide and calculating the percentage with associated streptococci (percent opsonization). The bactericidal activity of test antisera was determined using a similar assay except that fewer streptococci were added to the mixture, which was rotated for 3 hours at $37^{\circ} \mathrm{C}$. At the end of the rotation, 0.1$\mathrm{mL}$ aliquots were added to sheep blood agar, and pour plates were made to quantitate viable bacteria.

Determination of $L D_{50}$. A comparison of the mouse virulence of the M18 parent strain and the M18 $\Omega$ mutant was made after intraperitoneal challenge infections of Swiss white mice. Four groups of 6 mice each were challenged with 10 -fold increasing inocula, ranging from $2.7 \times 10^{4}$ to $2.7 \times 10^{7} \mathrm{CFU}$ of either M18 or M18 $\Omega$. Deaths were recorded for 7 days after challenge infections. The $\mathrm{LD}_{50}$ was determined by the method of Reed and Muench (17).

Passive mouse protection tests. Eight-week-old female white Swiss mice were given $0.5 \mathrm{~mL}$ of rabbit antiserum via the intraperitoneal route (2). After 24 hours, they were challenged using the same route with the indicated number of streptococci that had been grown to early log-phase in Todd-Hewitt broth. Deaths were recorded twice daily for 7 days.

Extraction and purification of Spa from pepsin extracts of $M 18 \Omega$. Extraction of peptide fragments from the surface of $M 18 \Omega$ was accomplished using dilute solutions of pepsin at suboptimal $\mathrm{pH}$, as described previously for the extraction of pep M proteins (18). The extract was precipitated in $60 \%$ saturated ammonium sulfate, dialyzed extensively against distilled water, and then lyophilized. The mixture of surface proteins and peptides is referred to as crude pep $M 18 \Omega$.

Spa was identified in the crude pepsin extract by opsonization inhibition assays. The crude pep $M 18 \Omega$ was separated by SDS-PAGE on a preparative $10 \%$ gel using reducing conditions. The entire gel was electroblotted to nitrocellulose paper, each end was cut vertically, and then these pieces were stained Coomassie brilliant blue to identify the protein bands. The center section of the nitrocellulose paper was cut into horizontal strips approximately $8-10 \mathrm{~mm}$ wide. Each strip was then used to absorb rabbit antiserum raised against the crude pep $\mathrm{M} 18 \Omega$ for 2 hours at $37^{\circ} \mathrm{C}$. Opsonization assays were performed using absorbed serum samples and unabsorbed serum, as described above. Once the opsonic inhibitory peptide had been identified

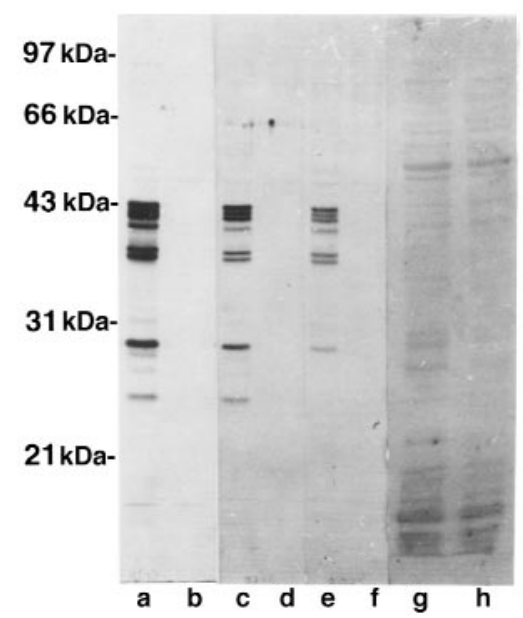

Figure 1

Western blot analysis of whole cell extracts of M18 (lanes a, $\mathbf{c}$, and $\mathbf{e}$ ) and $\mathrm{M} 18 \Omega$ (lanes $\mathbf{b}, \mathbf{d}$, and $\mathbf{f}$ ) reacted with rabbit antisera against $\mathrm{rM} 18$ (lanes $\mathbf{a}$ and b), SM18(1-30) (lanes $\mathbf{c}$ and $\mathbf{d}$ ), and SM5(265-291) (lanes e and f). Coomassie blue-stained multiple proteins in extracts from both strains (M18, lane $\mathbf{g}$; and $\mathrm{M} 18 \Omega$, lane $\mathbf{h}$ ). 
Table 2

Opsonization of $\mathrm{M} 18$ and $\mathrm{M} 18 \Omega$ by rabbit antisera against recombinant M18, S-M18(1-30), and crude pep M18

\begin{tabular}{lcc}
\hline \multicolumn{1}{c}{ Antiserum } & \multicolumn{2}{c}{$\begin{array}{c}\text { Percent neutrophils with } \\
\text { associated streptococci }\end{array}$} \\
& M18 & M SEM) \\
Preimmune pool & $0.7 \pm 0.7$ & $13.3 \pm 1.3$ \\
Anti-crude pep M18 & $98.7 \pm 0.7$ & $94.0 \pm 1.2$ \\
Anti-rM18 & $94.7 \pm 0.7$ & $15.3 \pm 0.7$ \\
Anti-SM18(1-30)-KLH & $95.3 \pm 0.7$ & $12.7 \pm 0.7$ \\
Anti-SM5(1-15)-KLH & $0.7 \pm 0.7$ & $15.3 \pm 0.7$
\end{tabular}

AEarly log-phase cultures of streptococci were added to $0.1 \mathrm{~mL}$ of test serum and incubated for 15 minutes at ambient temperature. To this was added $0.4 \mathrm{~mL}$ of normal, heparinized human blood, and the entire mixture was rotated end-over-end for 45 minutes at $37^{\circ} \mathrm{C}$. At the end of the rotation, a drop of each mixture was used to make thin smears on microscope slides. After staining the slides with Wright's stain, the percentage of neutrophils with associated streptococci (either ingested or attached) was estimated by counting at least 50 consecutive neutrophils. Experiments were repeated 3 times, and the data presented are the mean values \pm SEM . Anti-SM18(1-30)-KLH, rabbit antiserum against a synthetic peptide that copied the $\mathrm{NH}_{2}$-terminal 30 amino acids of M18 linked to $\mathrm{KLH}$. Anti-crude pep M18, rabbit antiserum against a partially purified pepsin extract of whole type 18 streptococci. Anti-SM5(1-15)-KLH, rabbit antiserum against a synthetic peptide that copied the $\mathrm{NH}_{2}$-terminal 15 amino acids of M5, which served as a control for the $\mathrm{KLH}$ antibodies in the SM18 antiserum.

in the crude pepsin extract, it was further purified by preparative gel electrophoresis (Prep Cell 491; Bio-Rad Laboratories Inc., Hercules, California, USA) by methods described previously (10).

Amino acid sequence analyses of Spa. The purified Spa protein was electrophoretically transferred to a polyvinylidene difluoride (PVDF) membrane and submitted to the Protein and Nucleic Acid Facility (Beckman Center, Stanford University Medical Center, Stanford, California, USA) for $\mathrm{NH}_{2}$-terminal sequencing by Edman degradation. The sequence of an internal peptide of Spa was also determined in the Stanford University Facility. The intact protein on PVDF was digested with LysC protease $(0.25 \mu \mathrm{mol} / \mathrm{mL})$ at $37^{\circ} \mathrm{C}$ overnight. The resultant peptides were purified by HPLC on a Vydac C18 column. Selected fractions were assessed for purity by mass spectroscopy, and 1 peptide with a mass of $1.249 \mathrm{kDa}$ was selected for $\mathrm{NH}_{2}$-terminal sequencing.

PCR, cloning, and sequencing a fragment of the spa18 gene. A fragment of the spa gene was amplified by PCR using degenerate inosine-containing oligonucleotide primers. The forward set of primers derived from the $\mathrm{NH}_{2}$-terminal sequence of Spa from amino acid residues $7-11$ contained the sequence GAR GTI GCI GAY CC. The reverse primers, from the $\mathrm{NH}_{2}$-terminal sequence of the internal peptide, contained the sequences RTG IGA YTC RCT RTC and RTG RCT YTC IGA RTC. PCR was performed as described previously (10) using chromosomal DNA from type 18 streptococci as the template. The forward primer in combination with the second reverse primer listed above resulted in a single PCR product of $336 \mathrm{bp}$, which was ligated into PCR2.1TOPO (Invitrogen Corp., San Diego, California, USA). DNA sequencing was performed by automated techniques in the University of Tennessee Molecular Resources Center using primers from the $5^{\prime}$ and $3^{\prime}$ flanking ends of the plasmid. The identity of the spa sequence was confirmed by comparing the translated DNA sequence to the amino acid sequence of Spa that was not used to construct the degenerate PCR primers.

An additional sequence of spa 18 was obtained by methods reported previously by Evans et al. (19). The 336-bp PCR product obtained above was purified, biotinylated, and then bound to streptavidin-coated magnetic beads. Chromosomal DNA from type 18 streptococci was partially digested with Sau3A and then ligated to synthetic oligonucleotide pairs (19) containing each half of the Sau3A sequence. The ligation mixture and bound PCR target were melted and mixed to capture spa-containing chromosomal sequences. The magnetic beads were washed, and then PCRs were performed using an internal spa primer and each of the 4 extension primers. PCR products were cloned into PCR2.1-TOPO, which was used to transform E. coli. Plasmids from positive transformants were screened for inserts and sequenced by automated techniques. One $\sim 600$-bp PCR product yielded an overlapping sequence plus 300 bases of a unique downstream sequence.

\section{Results}

Characterization of the $M$-negative mutant (M18 $\Omega$ ). The new streptococcal protective antigen was discovered during studies of an M-negative mutant of type 18 streptococci. The M-negative M18 strain was constructed by interrupting the emm 18 gene with an $\Omega$ element. Southern blot analyses of chromosomal DNA from M18 and M18 $\Omega$ strains were probed with $\Omega \mathrm{Km} 2$ and $e m m 18$ fragments and PCR analyses using primers from the emm gene and the $\Omega$ element; these probes revealed that there was a single copy of the $\Omega$ element inserted $\sim 140 \mathrm{bp}$ beyond the start codon of the emm 18 gene. In addition, PCR analyses using primers from the emm 18 gene revealed that there was not another copy of the emm 18 gene in the $M 18 \Omega$ strain (data not shown).

To confirm that the emm 18 gene was not expressed in the M18 $\Omega$ strain, immunoblots were performed using extracts of whole bacteria and rabbit antisera evoked by purified recombinant M18 (rM18), a synthetic peptide of M18, SM18(1-30), and synthetic peptide SM5(265-

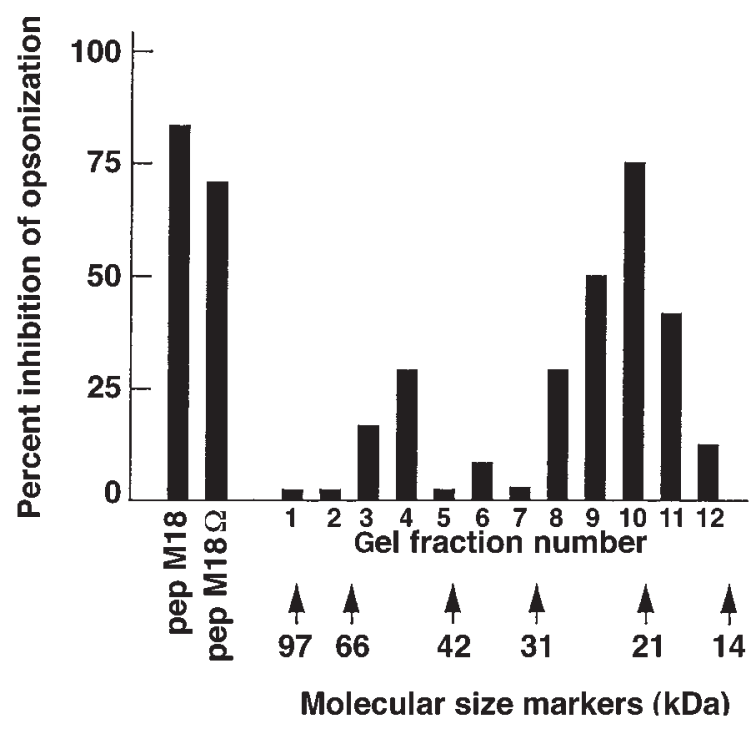

Figure 2

Identification of Spa in a crude pepsin extract of $M 18 \Omega$. The extract was separated by preparative PAGE, and the entire gel was transferred to nitrocellulose paper. Each bar, labeled 1-12, indicates the gel fraction that was used to absorb opsonic antibodies from a rabbit antiserum raised against a crude pepsin extract of $M 18 \Omega$ (see Methods). The unfractionated pepsin-extracted proteins from M18 and M18 $\Omega$ (labeled pep $\mathrm{M} 18$ and pep $\mathrm{M} 18 \Omega$, respectively) at a concentration of $1 \mathrm{mg} / \mathrm{mL}$ inhibited opsonization by $70-80 \%$. Absorption of the antiserum with gel fraction number 10, which contained a protein of approximately $24 \mathrm{kDa}$, resulted in a similar level of inhibition of opsonization. 
Table 3

Opsonization of type 18 streptococci by rabbit antisera against purified Spa and a synthetic peptide of Spa

Antiserum

Percent neutrophils with associated $\mathrm{M} 18$ $\operatorname{streptococci}^{\mathrm{A}}( \pm$ SEM)

$0.7 \pm 0.7$

$97.3 \pm 0.7$

$72.7 \pm 1.8$

$94.7 \pm 0.7$

Anti-S-Spa(1-23)C

Anti-rM18

ADetails of the assay are provided in the legend to Table 2. Experiments were performed 3 times, and the data presented are the mean values \pm SEM. Anti-S-Spa (1-23)C, rabbit antiserum against a synthetic peptide that copied the $\mathrm{NH}_{2}$-terminal 23 amino acids of Spa linked to KLH.

291), which copies the C-repeat domain of type $5 \mathrm{M}$ protein that is common to all M proteins (1) (Figure 1). Rabbit antiserum against intact, recombinant type $18 \mathrm{M}$ protein (anti-rM18) reacted with a triplet of proteins extracted from the parent strain, the largest of which had a molecular mass of $\sim 43 \mathrm{kDa}$ (Figure 1, lane a). The immunoreactive proteins with lower molecular mass are presumably degradation products of M18 that were present in the crude extracts of whole bacteria. There was no reaction of rM18 antiserum with the extract from the M18 $\Omega$ mutant (Figure 1, lane b). Anti-SM18(1-30) reacted only with proteins in extracts from the parent strain (Figure 1, lane c), and the pattern was identical to that observed with antiserum against rM18. Interestingly, antiserum against the $\mathrm{C}$-repeat peptide of $\mathrm{M}$ protein, SM5(265-291), reacted only with an extract from the parent strain (Figure 1, lane e) and not with an extract from the mutant (Figure, lane $\mathrm{f}$ ). This suggests that the mutant did not express another $\mathrm{M}$ protein or M-like protein containing these shared repeating epitopes. These data, taken together with the results of the Southern blot analyses and PCR, indicate that the $\Omega$ element was inserted in the emm 18 gene and that the M18 protein was not expressed by $\mathrm{M} 18 \Omega$.

Growth in blood and mouse virulence of $M 18$ and $M 18 \Omega$.. The virulence of the M-negative mutant of type 18 streptococci was first assessed by its ability to grow in nonimmune human blood (Table 1). The parent strain of M18 grew to just over 8 generations after a 3-hour rotation in blood. The M18 $\Omega$ mutant grew to approximately 7.5 generations in the same assay. The most stringent laboratory assay for virulence is intraperitoneal challenge infections of nonimmune mice. The $\mathrm{LD}_{50}$ of M18 and $\mathrm{M} 18 \Omega$ were calculated after intraperitoneal injections of 10 -fold increasing doses of each organism. The $\mathrm{LD}_{50}$ of the parent M18 strain was $0.73 \times 10^{5}$, and the $\mathrm{LD}_{50}$ of the $\mathrm{M} 18 \Omega$ was 1.26 $\times 10^{5}$. Of the 24 mice challenged with each organism, 8 challenged with M18 died, and 7 challenged with M18 $\Omega$ died. Organisms recovered from the spleens of mice that succumbed to challenge infections with $\mathrm{M} 18 \Omega$ were kanamycin resistant and M18 negative, indicating that there was no reversion to the parent phenotype in vivo. These results demonstrated that the expression of M18 was not required for virulence of type 18 streptococci.

Opsonization of $M 18$ and $M 18 \Omega$. Interruption of emm 18 expression could have resulted in a virulent mutant that did not express a protective antigen, or alternatively, one that expressed a second protective antigen on its surface. In vitro opsonization experiments were performed to determine whether $M 18 \Omega$ expressed a surface antigen that contained opsonic epitopes (Table 2). Only the M18 parent strain was opsonized by antisera against SM18(130) or recombinant M18. The association of $M 18 \Omega$ with polymorphonuclear neutrophils remained at baseline levels in the presence of both of these antisera. Antiserum raised in rabbits against a crude pepsin extract of the M18 $\Omega$ strain, however, opsonized both the parent and the M-negative mutant (Table 2). This antiserum was used in subsequent experiments to identify and purify the putative new protective antigen of type 18 streptococci.

Identification and purification of Spa. To identify the surface antigen of $M 18 \Omega$ containing opsonic epitopes, we performed opsonization inhibition experiments using fractions of the crude pepsin extract of $M 18 \Omega$ that had been separated by SDS-PAGE and then transferred to nitrocellulose paper. One section of the nitrocellulose paper was reacted with pep $M 18 \Omega$ antiserum to identify the immunoreactive bands, and another section was cut into horizontal strips that were used to absorb opsonic antibodies in the pep $M 18 \Omega$ antiserum. The pep $M 18 \Omega$ extract contained a protein with a molecular mass of 24 $\mathrm{kDa}$ (Spa) that absorbed the majority of the opsonic antibodies in the pep M18 $\Omega$ antiserum (Figure 2).

Spa was purified from the crude pepsin extract of $\mathrm{M} 18 \Omega$ by ammonium sulfate precipitation and preparative gel electrophoresis. The purified Spa migrated as a single band, as assessed by SDS-PAGE, with a molecular mass of $24 \mathrm{kDa}$ (Figure 3b). Edman degradation of the purified protein revealed the sequence of the first 23

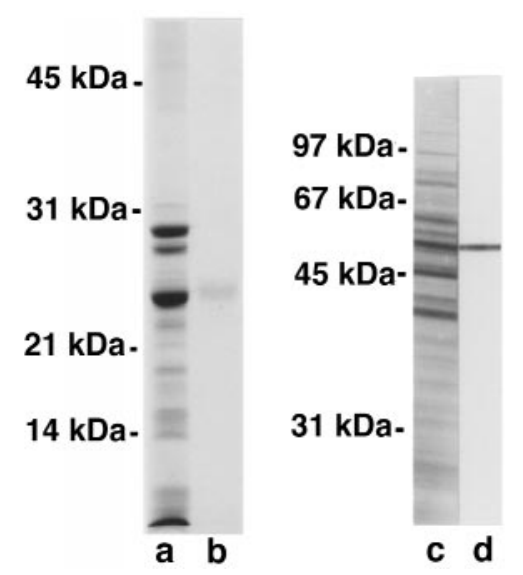

Figure 3

PAGE of the purified fragment of Spa (lanes $\mathbf{a}$ and $\mathbf{b}$ ) and Western blot analysis of the native protein extracted by phage lysin (lanes $\mathbf{c}$ and $\mathbf{d}$ ). The crude pep $M 18 \Omega$ (lane a) and the purified Spa (lane b) were electrophoresed in a $10 \%$ polyacrylamide gel under reducing conditions and stained with Coomassie blue. The purified Spa migrated with a molecular mass of $24 \mathrm{kDa}$. Western blot analysis was performed to identify the native Spa that was released from the cell wall of $M 18 \Omega$ by group $C$ streptococcal phage-associated lysin (19). The crude lysin extract contained multiple proteins that stained with Coomassie blue (lane c). Antiserum against the synthetic peptide of Spa reacted with a single protein in the extract with a molecular mass of $50 \mathrm{kDa}$ (lane d). 
Table 4

Bactericidal activity of rabbit antisera against rM18 and purified Spa against $\mathrm{M} 18$ and $\mathrm{M} 18 \Omega$

CFU surviving a 3-hour rotation ${ }^{A}$

\begin{tabular}{|c|c|c|}
\hline \multirow[t]{2}{*}{ Antiserum } & M18 & $\mathrm{M} 18 \Omega$ \\
\hline & Inoculum: 16 & 19 \\
\hline Normal rabbit serum & 2,300 & 3,780 \\
\hline Anti-rM18 & 80 & 3,860 \\
\hline Anti-Spa & 150 & 0 \\
\hline Anti-rM18 + anti-Spa & 0 & ND \\
\hline
\end{tabular}

Alndirect bactericidal assays were performed by adding a small inoculum of the wildtype (M18) or the M-negative mutant $(\mathrm{M} 18 \Omega$ ) to $0.4 \mathrm{~mL}$ of nonimmune human blood that contained $0.1 \mathrm{~mL}$ of test rabbit antiserum. The mixtures were rotated end-over-end for 3 hours at $37^{\circ} \mathrm{C}$, and the organisms surviving were quantitated on pour plates of sheep blood agar. The experiment was performed 3 times with similar results. The data presented are from a representative experiment. Anti-rM18 + anti-Spa, a 50:50 mixture of the 2 antisera added to the test mixture in a total volume of $0.1 \mathrm{~mL}$. ND, not done.

amino acids to be DSVSGLEVADPSDSKKLIELGLA. In addition, an internal peptide purified from a LysC digest of the intact $\mathrm{Spa}$ ontained the $\mathrm{NH}_{2}$-terminal sequence YRLDSESHLK.

Bactericidal activity of Spa antibodies. To directly assess the presence of bactericidal epitopes in Spa, rabbits were immunized with $100 \mu \mathrm{g}$ of the purified protein in CFA at 0,4 , and 8 weeks. Antiserum obtained 10 weeks after the first injection contained antibodies that opsonized the M18 parent and M18 $\Omega$ (Table 3). None of the Spa antisera cross-reacted with purified recombinant M18 or purified recombinant Enn18, as determined by ELISA (data not shown). The results of the opsonization assays were confirmed by indirect bactericidal tests (Table 4). The Spa antiserum was bactericidal against both $\mathrm{M} 18$ and $\mathrm{M} 18 \Omega$. Antiserum against rM18 was bactericidal against only the parent M18 strain and not against M18 $\Omega$ (Table 4). A mixture of Spa and rM18 antisera resulted in complete killing of the M18 parent strain, suggesting that the 2 antisera have an additive bactericidal effect (Table 4).

Passive mouse protection tests with anti-Spa and anti-rM18. Passive mouse protection tests were performed to demonstrate the presence of protective epitopes within
Spa. In both experiments, groups of 10 mice each were pretreated with either anti-Spa, anti-rM18, or an equal mixture of the 2 antisera, and then later challenged with M18 or M18 $\Omega$ (Table 5). Of the mice challenged with the parent M18 strain, only 3 out of 20 control animals survived. Those pretreated with anti-rM18 or anti-Spa had higher rates of survival, but these were not statistically different from the control group. Interestingly, the mice that received a mixture of anti-Spa and anti-rM18 were significantly protected from challenge infections with the parent M18 strain (Table 5). Of the mice challenged with $\mathrm{M} 18 \Omega$, those that were pretreated with anti-Spa alone were significantly protected from death when compared with the control animals receiving normal rabbit serum (Table 5). Taken together, these results directly demonstrate the presence of protective epitopes within Spa.

Identification of opsonic epitopes within the $\mathrm{NH}_{2}$-terminus of Spa. To confirm the presence of opsonic epitopes within the covalent structure of Spa, a peptide [S-Spa18(1-23)C] copying the $\mathrm{NH}_{2}$-terminal 23 amino acids of the purified $24-k D a$ fragment was chemically synthesized. The peptide was covalently linked to KLH (11), and 3 rabbits were immunized with $100-\mu \mathrm{g}$ doses using the same schedule described above. Serum from all 3 rabbits opsonized both the parent and M18 $\Omega$ strains of group A streptococci (Table 3), confirming the presence of opsonic epitopes within this limited region of Spa. The antiserum against the synthetic peptide of Spa was also used to identify the native protein in phage lysin extracts of $\mathrm{M} 18 \Omega$ (20). The S-Spa18(1-23)C antiserum reacted in the lysin extract with a single protein with a molecular mass of $50 \mathrm{kDa}$ (Figure $3 \mathrm{~d}$ ), suggesting that the pepsinderived Spa was a fragment of the larger native protein.

Opsonization of heterologous serotypes of group A streptococci by Spa antiserum. To determine whether Spa evoked opsonic antibodies against serotypes of group A streptococci other than type 18, opsonization assays were performed with antisera against purified Spa or against the pep M18 $\Omega$ and a series of selected streptococci (Table 6). Both antisera opsonized type 3 and type 28 streptococci, in addition to type 18 organisms. Serotypes tested that were not opsonized by either antiserum were M1, M2, M5, M6, M13, M14, M19, and M24, all of which

Table 5

Passive protection of mice against challenge infections with M18 or M18 $\Omega$ by rabbit antisera against $\mathrm{rM} 18$ and Spa

No. mice surviving/No. mice challenged with ${ }^{A}$

M18

$\begin{array}{lccc}\text { Antiserum } & \text { Exp. no. } 1 & \text { Exp. no. } 2 & \text { Total } \\ \text { Inoculum } & 1.2 \times 10^{7} & 2.5 \times 10^{7} & \\ & & & \\ \text { Normal rabbit serum } & 2 / 10 & 1 / 10 & 3 / 20 \\ \text { Anti-rM18 } & 4 / 10 & 3 / 10 & 7 / 20(\mathrm{NS}) \\ \text { Anti-Spa } & 3 / 10 & 2 / 10 & 5 / 20(\mathrm{NS}) \\ \text { Anti-rM18 + anti-Spa } & 7 / 10 & 9 / 10 & 16 / 20(P=0.0001)\end{array}$

$\mathrm{M} 18 \Omega$

$\begin{array}{ccc}\text { Exp. no. } 1 & \text { Exp. no. } 2 & \text { Total } \\ 1.8 \times 10^{7} & 4.0 \times 10^{7} & \\ & & \\ 5 / 10 & 1 / 10 & 6 / 20 \\ \text { ND } & \text { ND } & \\ 9 / 10 & 8 / 10 & 17 / 20(P=0.001) \\ \text { ND } & \text { ND }\end{array}$

APassive mouse protection tests were performed according to the original protocol described by Lancefield (2). Briefly, white Swiss mice were injected via the intraperitoneal route with $0.5 \mathrm{~mL}$ of rabbit serum and then challenged 24 hours later with virulent streptococci from early log-phase cultures. Deaths were recorded twice daily for a total of 7 days. Each experiment was performed using an identical protocol, with the exception that in experiment no. 2, the pooled antisera against $\mathrm{rM} 18$ and Spa were concentrated to $50 \%$ of the original volume and each animal received $0.5 \mathrm{~mL}$. Statistical analyses were performed using a $\chi^{2}$ test on MultiStat software (Biosoft, Cambridge, United Kingdom). 


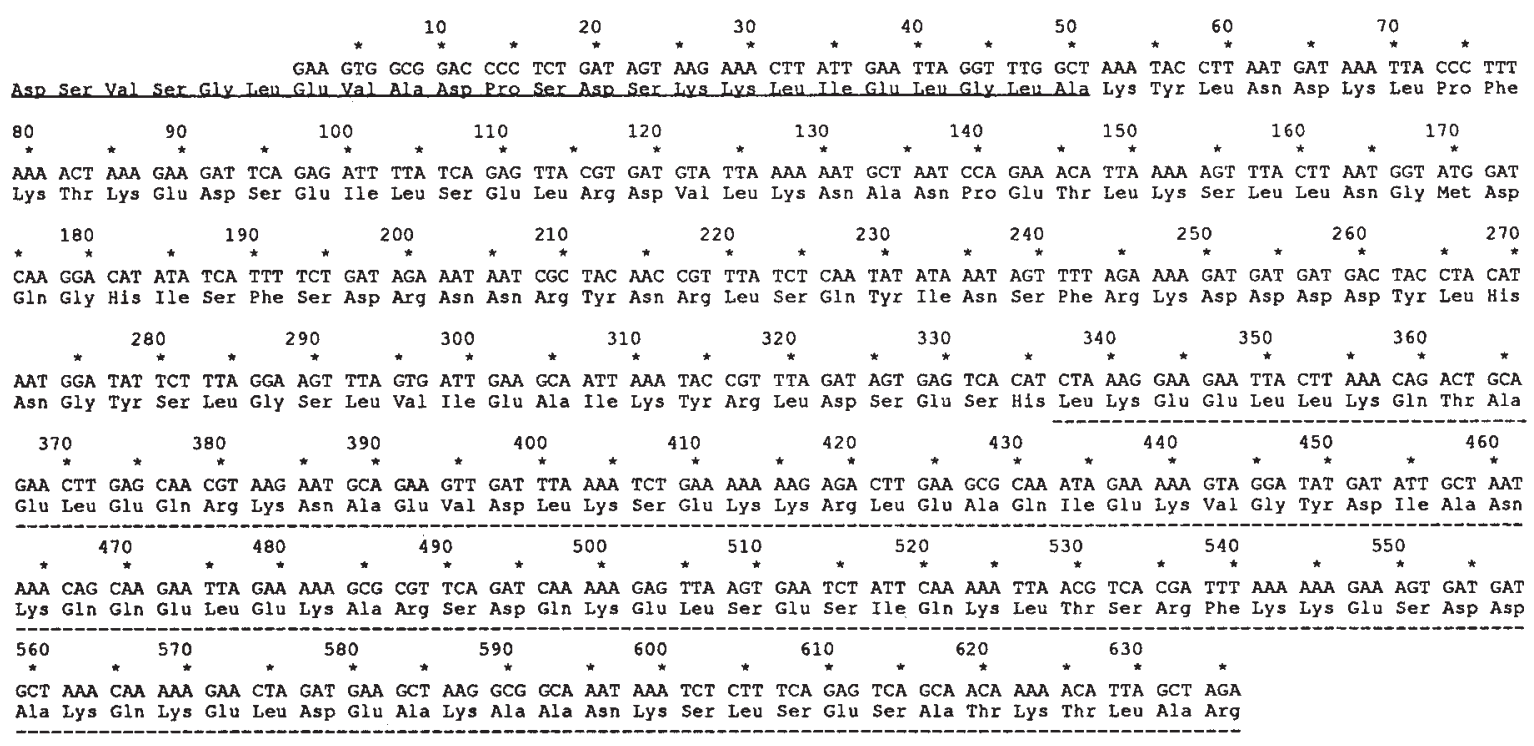

Figure 4

Partial DNA sequence of the spa gene and the deduced amino acid sequence. The solid underline indicates the amino acid sequence of purified Spa determined by Edman degradation. The unmarked DNA sequence (bases 1-336) was determined from the PCR product obtained using chromosomal DNA and degenerate oligonucleotide primers based on the $\mathrm{NH}_{2}$-terminal and internal amino acid sequences. The dashed line indicates the sequence derived from an overlapping DNA fragment that was captured from a Sau3A digest of chromosomal M18 DNA using the original 336-bp PCR fragment. The sequence has been submitted to GenBank and has the accession no. AF086813.

were from our laboratory collection. The anti-SSpa18(1-23)C antisera did not opsonize types 3 or 28 streptococci, indicating that this limited region of Spa does not contain cross-opsonic epitopes.

Cloning and sequencing a fragment of the spa18 gene. A fragment of the spa18 gene was cloned using PCR and degenerate primers based on the $\mathrm{NH}_{2}$-terminal peptide sequence and the sequence of an internal peptide purified from a LysC digest of Spa. The PCR product was $336 \mathrm{bp}$ in length, and the translated amino acid sequence contained residues $12-23$ of the sequence derived from the Spa protein (Figure 4), confirming that the DNA was a fragment of spa18. An additional sequence of spa 18 was obtained from an overlapping Sau3A fragment of chromosomal DNA that was captured using the original PCR fragment (Figure 4). A search of the current entries in GenBank and the type 1 streptococcal genome sequence database (http://dna1.chem.ou.edu/strep.html) revealed that the 636-bp spa18 gene fragment did not share sequence homology with any known proteins, suggesting that Spa is a new protective antigen of group A streptococci.

\section{Discussion}

Previous studies have shown that the surface $M$ proteins of group A streptococci play a dual role in the pathogenesis of infection. M proteins are a major determinant of virulence and confer upon group A streptococci the ability to resist phagocytosis and killing by neutrophils (2). In addition, $M$ proteins elicit bactericidal antibodies thought to protect the host against subsequent infection by the same serotype (2). The antibodies with the greatest bactericidal activity are directed against the $\mathrm{NH}_{2}$-terminal, hypervariable epitopes of M proteins (21-24). Among the many defined surface proteins of group A streptococci, only antibodies against the $\mathrm{M}$ protein have been shown to be opsonic. In the present study, however, we have identified a new protective antigen, distinct from $M$ protein, that evokes bactericidal antibodies.

The identification of Spa was facilitated by the fact that the M-negative mutant of type 18 streptococci was fully virulent when compared with the parent strain. This finding is somewhat contradictory to the recent results of Moses et al. (14), who showed reduced virulence of an M-negative mutant of the same M18 strain (87-282). They concluded that the hyaluronate capsule and the surface $M$ protein played significant but unequal roles in resistance to phagocytosis and in mouse virulence. The identification of Spa in this strain raises the possibility that it too may play a role in virulence. This has not yet been tested directly, but experiments are now underway to create a Spa-negative/M-negative mutant that will be assessed for mouse virulence and its ability to grow in human blood.

The concept that group A streptococci may express more than 1 surface protein that contains protective epitopes is not new, but to date there has been insufficient data to prove the hypothesis. As early as 1939, Hirst and Lancefield (25) reported cross-protective antisera raised against crude extracts of different serotypes of group A streptococci. Wiley and Wilson (26) later reported the occurrence of $2 \mathrm{M}$ antigens on the surface of certain strains of type 14 organisms. Other similar studies reported cross-protective immune responses evoked by various antigen preparations $(27,28)$. We now recognize that some $\mathrm{M}$ proteins contain cross-protective and typespecific epitopes (29). However, none of these earlier studies provided definitive evidence that any of the organisms actually expressed 2 distinct surface proteins containing protective epitopes. 
A more recent study of cross-protective immunity by Chappell and Stuart (30) may be directly related to the protective epitopes of Spa. In these experiments, mice that were parentally immunized with an M-negative mutant of type 28 streptococci were protected against intravenous challenge infections with the type 28 parent and types 3 and 18 streptococci. In addition to the apparent non-M protein-mediated protective immune responses, the investigators also observed that the type $28 \mathrm{M}$-negative mutant was as virulent in mice as the Mpositive type 3 and type 18 strains (30). Our finding that rabbit antisera against Spa opsonized all 3 of these serotypes suggests that the cross-protective immune responses observed by these investigators may have indeed been evoked by a Spa-like protein on the surface of type 28 streptococci.

In the present studies, we have shown that opsonic epitopes reside on both the M18 protein and Spa18. Both proteins evoked antibodies in rabbits that were bactericidal against the parent M18 strain in human blood. Although a greater number of mice survived when treated with anti-M18 or anti-Spa18 than when treated with preimmune serum, neither antiserum alone provided statistically significant protection against challenge infections of mice with the parent strain. Only the mice that received a mixture of the 2 antisera were protected to a statistically significant degree. Although these results suggest that both antigens may be required to evoke a fully protective immune response, we have not ruled out the possibility that our findings simply reflect the absolute quantity of antibodies against rM18 or Spa in each of the immune rabbit sera. Studies are currently in progress to quantitate the relative role of each antibody population in bactericidal killing.

The identification of Spa raises many questions that remain to be answered. Experiments to determine the complete sequence of the spa gene and its position in the streptococcal chromosome are currently in progress, as are experiments to determine the frequency of the gene and its expression by other serotypes of group A streptococci. Other important questions relate not only to the prevalence of spa within different strains of type 18 streptococci but also to the regulation of its expression. Type 18 streptococci have been identified as an important serotype in the resurgence of acute rheumatic fever in Utah (31). In addition, types 3 and 18, and to a lesser extent type 28, streptococci have all been implicated in the recent resurgence of serious streptococcal diseases (32). Differential expression of spa could potentially result in new subtypes of the organism with different virulence characteristics that may be partly defined by the immune status of the host and the population as a whole. The ability of an individual $M$ serotype to alter the protective antigens expressed on its surface could potentially impact the changing epidemiology of group A streptococcal infections.

The discovery of a new protective antigen of group A streptococci has obvious implications for the development of vaccines that would prevent these infections. Our current approach is to use limited $\mathrm{NH}_{2}$-terminal fragments of $\mathrm{M}$ proteins that are linked in tandem to evoke protective immune responses against each

\section{Table 6}

Opsonization of heterologous serotypes of group A streptococci by rabbit antisera against purified Spa and a crude pepsin extract of M18 $\Omega$

Percent neutrophils with associated streptococci ${ }^{\mathrm{A}}$ $( \pm$ SEM) in the presence of

$\begin{array}{lccc}\text { Serotype (strain) } & \begin{array}{c}\text { Normal rabbit } \\ \text { serum }\end{array} & \begin{array}{c}\text { Anti-crude } \\ \text { pep M18 } \Omega\end{array} & \text { Anti-Spa } \\ \text { M18(282) } & 0.6 \pm 0.7 & 91.3 \pm 0.7 & 96.7 \pm 0.7 \\ \text { M3 (3375) } & 1.3 \pm 0.7 & 59.3 \pm 1.3 & 26.0 \pm 1.2 \\ \text { M28 (S2356) } & 1.3 \pm 0.7 & 17.3 \pm 1.3 & 25.3 \pm 1.8\end{array}$

${ }^{A}$ Details of the assay are provided in the legend to Table 2. Serotypes that were tested but were not opsonized by either antiserum were M1, M2, M5, M6, M13, M14, $\mathrm{M} 19$, and M24. Experiments were repeated 3 times, and the data presented are the mean values \pm SEM.

serotype represented in the vaccine $(10,23,24)$. This has the advantage of limiting the total amount of protein contained in the vaccine. However, because each $\mathrm{NH}_{2}$ terminal $\mathrm{M}$ protein fragment is type specific, this will likely necessitate the development of relatively complex vaccines to prevent the majority of streptococcal infections in a given population or geographic region. If Spa and Spa-like proteins are found to elicit significant cross-protection, this could facilitate the development of broadly protective vaccines that are considerably less complex than those presently in development.

To our knowledge, this is the first study to show that group A streptococci may express 2 distinct surface proteins that contain opsonic epitopes. Whether Spa is involved directly in the pathogenesis of streptococcal infections is not yet known. We believe that continued studies of Spa and related proteins that may be expressed by other serotypes of group A streptococci will provide new insights into the pathogenesis of these infections and the protective immune responses that they elicit.

\section{Acknowledgments}

The authors thank Valerie Long and Yi Li for expert technical assistance. The protein sequencing was performed by Dick Winant and Al Smith in the Protein and Nucleic Acid Facility at the Beckman Center for Molecular and Genetic Medicine, Stanford University. The authors also thank Philip Potter (St. Jude Children's Research Hospital Memphis, Tennessee, USA) for advice on the design of degenerate PCR primers. This work was supported by research funds from the US Department of Veterans Affairs (to J.B. Dale and D.L. Hasty), the National Institutes of Health (grant AI-10085 to J.B. Dale), and ID Vaccine Corporation.

\footnotetext{
1. Fischetti, V.A. 1989. Streptococcal M protein: molecular design and biological behavior. Clin. Microbiol. Rev. 2:285-314.

2. Lancefield, R.C. 1962. Current knowledge of the type-specific M antigens of group A streptococci. J. Immunol. 89:307-313.

3. Caparon, M.G., and Scott, J.R. 1987. Identification of a gene that regulates expression of $\mathrm{M}$ protein, the major virulence determinant of group A streptococci. Proc. Natl. Acad. Sci. USA. 84:8677-8681.

4. Hollingshead, S.K., Readdy, T.L., Yung, D.L., and Bessen, D.E. 1993. Structural heterogeneity of the $\mathrm{emm}$ gene cluster in group A streptococci. Mol. Microbiol. 8:707-717.

5. Perez-Casal, J., Caparon, M.G., and Scott, J.R. 1992. Introduction of the emm 6 gene into and emm-deleted strain of Streptococcus pyogenes restores its ability to resist phagocytosis. Res. Microbiol. 143:549-558.

6. Courtney, H.S., Bronze, M.S., Dale, J.B., and Hasty, D.L. 1994. Analysis of the role of M24 protein in streptococcal adhesion and colonization by use of omega-interposon mutagenesis. Infect. Immun. 62:4868-4873.
} 
7. Podbielski, A., Schnitzler, N., Beyhs, P., and Boyle, M.D.P. 1996. M-related protein (Mrp) contributes to group A streptococcal resistance to phagocytosis by human granulocytes. Mol. Microbiol. 19:429-441.

8. Dale, J.B., Washburn, R.G., Marques, M.B., and Wessels, M.R. 1996. Hyaluronate capsule and surface M protein in resistance to phagocytosis of group A streptococci. Infect. Immun. 64:1495-1501.

9. Wessels, M.R., Moses, A.E., Goldberg, J.B., and DiCesare, T.J. 1991. Hyaluronic acid capsule is a virulence factor for mucoid group A streptococci. Proc. Natl. Acad. Sci. USA. 88:8317-8321.

10. Dale, J.B., Chiang, E.Y., and Lederer, J.W. 1993. Recombinant tetravalent group A streptococcal M protein vaccine. J. Immunol. 151:2188-2194.

11. Dale, J.B. and Beachey, E.H. 1986. Localization of protective epitopes of the amino terminus of type 5 streptococcal M protein. J. Exp. Med. 163:1191-1202.

12. Sambrook, J., Fritsch, E.F., and Maniatis, T. 1989. Molecular cloning: a laboratory manual. Cold Spring Harbor Laboratory Press. Cold Spring Harbor, NY.

13. Dale, J.B., and Beachey, E.H. 1985. Multiple, heart cross-reactive epitopes of streptococcal M proteins. J. Exp. Med. 161:113-122.

14. Moses, A.L., et al. 1997. Relative contributions of hyaluronic acid capsule and $\mathrm{M}$ protein to virulence in a mucoid strain of the group A streptococcus. Infect. Immun. 65:64-71.

15. Chen, C., and Cleary, P.P. 1990. Complete nucleotide sequence of the C5a peptidase gene of Streptococcus pyogenes. J. Biol. Chem. 265:3161-3167.

16. Beachey, E.H., et al. 1977. Purification and properties of M protein extracted from group A streptococci with pepsin: covalent structure of the amino terminal region of the type $24 \mathrm{M}$ antigen. J. Exp. Med. 145:1469-1481.

17. Reed, L.J., and Muench, H. 1938. A simple method for estimating fifty percent endpoints. Am. J. Hyg. 27:493-499.

18. Beachey, E.H., Campbell, G.L., and Ofek, I. 1974. Peptic digestion of streptococcal M protein. II. Extraction of M antigen from group A streptococci with pepsin. Infect. Immun. 9:891-896.

19. Evans, D.J., Evans, D.G., Lampert, H.C., and Nakano, H. 1995. Identification of four new prokaryotic bacterioferritins from Helicobacter pylori, Anabaena variabilis, Bacillus subtilis and Treponema pallidum, by analysis of gene sequences. Gene. 153:123-127.

20. Zabriskie, J.B., and Freimer, E.H. 1966. An immunological relationship between the group A streptococcus and mammalian muscle. J. Exp. Med. 124:661-678

21. Dale, J.B., Seyer, J.M., and Beachey, E.H. 1983. Type-specific immunogenicity of a chemically synthesized peptide fragment of type 5 streptococcal M protein. J. Exp. Med. 158:1727-1732.

22. Jones, K.F. and Fischetti, V.A., 1988. The importance of the location of antibody binding on the M6 protein for opsonization and phagocytosis of group A M6 streptococci. J. Exp. Med. 167:1114-1123.

23. Dale, J.B., Simmons, M., Chiang, E.C., and Chiang, E.Y. 1996. Recombinant, octavalent group A streptococcal $M$ protein vaccine. Vaccine. 14:944-948.

24. Dale, J.B. 1999. Multivalent group A streptococcal vaccine designed to optimize the immunogenicity of six tandem M protein fragments. Vaccine. 17:193-200.

25. Hirst, G.K., and Lancefield, R.C. 1939. Antigenic properties of the typespecific substances derived from group A hemolytic streptococci. J. Exp. Med. 69:425-438.

26. Wiley, G.G., and Wilson, A.T. 1960. The occurrence of two M antigens in certain group A streptococci related to type 14. J. Exp. Med. 113:451-460.

27. Wiley, G.G., and Bruno, P.N. 1968. Cross-reaction among group A streptococci. I. Precipitin and bactericidal cross-reactions among types 33,41 , 43, 52, and Ross. J. Exp. Med. 128:959-972.

28. Bergner-Rabinowitz, S., Ofek, I., and Moody, M.D. 1972. Cross-protection among serotypes of group A streptococci. J. Infect. Dis. 125:339-347.

29. Dale, J.B., and Beachey, E.H. 1984. Unique and common protective epitopes among different serotypes of group A streptococcal M proteins defined with hybridoma antibodies. Infect. Immun. 46:267-269.

30. Chappell, J.D., and Stuart, J.G. 1993. Demonstration of protection in mice from a lethal challenge of three M serotypes of Streptococcus pyogenes using an M-negative vaccine. Vaccine. 11:643-649.

31. Veasy, L.G., et al. 1987. Resurgence of acute rheumatic fever in the intermountain area of the United States. N. Engl. J. Med. 316:421-427.

32. Johnson, D.R., Stevens, D.L., and Kaplan, E.L. 1992. Epidemiologic analysis of group A streptococcal serotypes associated with severe systemic infections, rheumatic fever, or uncomplicated pharyngitis. J. Infect. Dis. 166:374-382. 